\title{
DESARROLLO LOCAL Y PATRIMONIO CULTURAL. EL PARQUE CULTURAL DE ALBARRACÍN*1
}

\author{
P. Rubio Terrado \\ Grupo de Investigación GEDETUZ \\ Dpto. de Geografía y Ordenación del Territorio \\ Universidad de Zaragoza \\ pasrubio@unizar.es
}

\begin{abstract}
Resumen: El patrimonio cultural deriva del comportamiento colectivo de un pueblo en un lugar y un tiempo y forma parte consustancial de la dimensión territorial. Constituye un ejemplo de recurso endógeno al que se adjudica un alto potencial de desarrollo en la escala local, en una doble dimensión, económica, como agente y bien mercantil mediante su aprovechamiento turístico, y social, como elemento de identidad. En Aragón, la Ley 12/1997 de Parques Culturales aporta un marco normativo propio para la gestión-protección del patrimonio cultural desde el fin genérico de la ordenación global sostenible de ámbitos rurales con valores patrimoniales y paisajístico-ambientales cuya singularidad constituye un elemento estructurante del territorio. Propone un modelo de desarrollo económico y social alternativo al productivista y relacionado con la emergencia de un enfoque postmoderno de multifuncionalidad flexible. El desarrollo de la ley ha dado lugar a la delimitación de cinco parques, entre ellos el de Albarracín.
\end{abstract}

Palabras clave: Recursos territoriales, desarrollo local sostenible, patrimonio cultural, parque cultural, turismo cultural.

The cultural patrimony derives from the collective behavoir of a people in a place and a time and forms a part consubstantially of the territorial dimension. It constitutes an example of endogenous resource to which an high potential place of development is awarded in the local scale, in a double dimension, economic, as agent and mercantile by means of its tourist utilization, and social, as element of identity. In Aragon, the Law 12/1997 of Cultural Parks contributes a own normative frame for the management-protection of the cultural patrimony from the generic purpose of the global sustainable arrangement of rural areas

\footnotetext{
* Recibido: 15-11-07. Aceptado: 24-04-08

${ }^{1}$ El texto de este artículo toma como base la comunicación presentada por el mismo autor, en colaboración con P. L. Hernando, en el III Coloquio Hispano-Francés de Geografía Rural Espacios Naturales Protegidos, Baeza, 28-30 de mayo de 2007.
} 
with patrimonial and landscape-environmental values which singularity constitutes an estructurante element of the territory. There proposes a model of economic and social alternative development productivist and related to the emergency of a postmodern approach of flexible multifunctionality. The development of the law has given place to the delimiting of five parks, among them that of Albarracín.

Keywords: Territorial resources, local sustainable development, cultural patrimony, cultural park, cultural tourism.

\section{Introducción}

Coincidimos con Claval (2002) cuando señala que el espacio no es un soporte neutro de la vida social, antes bien, se asemeja a un texto cargado de mensajes que le otorgan un sentido propio en cada lugar. El grupo social es responsable de la adquisición de ese sentido, sin olvidar, tampoco, el papel individual del ser humano, capaz de adoptar decisiones no siempre concordes con las tendencias y procesos generales; el grupo organiza y modela el espacio formando el territorio, de acuerdo con su sistema valores, capacidades científico-técnicas, necesidades, creencias y características del soporte natural. También su localización influye, en un doble sentido, a escala "macro" lo hace sobre las interacciones entre cada territorio y su entorno y en la integración o aislamiento con respecto a él, mientras que en la "micro" interviene en la actuación concreta de los individuos en su espacio. El territorio es, en definitiva, una elaboración humana en cuya construcción es básica la cultura en cuanto que producto del "sistema de criterios consensuados que una comunidad humana tiene para una conducta correcta y eficaz, específica para un lugar y un tiempo" (Wagner, 2002: 44), lo que deriva en la aparición de marcadas identidades territoriales.

La identidad se plasma en la elaboración de un hecho cultural concreto formado por la combinación de diferentes elementos de la cultura, al modo de un escenario (Claval, 2002) que se ha ido concretando de forma progresiva y acumulativa, teniendo en cuenta el sentido que los seres humanos dan en cada momento al espacio que les rodea y en el que viven. Esa construcción origina un paisaje calificable de patrimonio cultural o, como señala Ruiz (2004), patrimonio territorial, sobre el que han influido tanto los procesos generales (económicos, demográficos, tecnológicos, etcétera) como las particularidades culturales propias de lo local (Albertos, 2002), no en vano "la cultura es también un comportamiento adaptado a una situación particular y que alcanza todas las relaciones de un individuo y un grupo consigo mismo, con los demás o con la naturaleza" (Limgruber, 2002: 92). La identidad territorial tenderá a ser tanto más acentuada cuanto mayor haya sido el aislamiento con el entorno, o también cuando 
el medio local haya influido aportando singularidades significativas (litológicas, topográficas, climáticas, etcétera) que hayan colaborado en modelar la cultura. El aislamiento, más probable en los ámbitos de montaña, cuando haya sido importante y duradero en el tiempo, explicará bien la existencia de culturas singulares.

El patrimonio cultural es un valor en sí mismo y también se considera un recurso endógeno importante para el desarrollo socioeconómico a la escala local. Ocio y cultura se dan la mano en la sociedad actual y el turismo cultural es la interfase que los conecta; las orientaciones posibles de ese turismo son varias, cultural, verde o simplemente buscando la tranquilidad, y como actividad económica está cada vez más presente en el medio rural, frecuentemente en un contexto de innovación con respecto al modelo territorial tradicional, derivado de la aplicación de políticas públicas de desarrollo, entre ellas la de parques culturales.

La finalidad básica de este trabajo consiste en reflexionar sobre la participación de los hechos culturales en la ordenación, desarrollo y gestión del territorio, teniendo en cuenta la transversalidad que anima a la cultura. Para ello particularizaremos en un pequeño ámbito espacial en el entorno de Albarracín, por su carácter de parque cultural al amparo de la Ley 12/1997 de 3 diciembre de Parques Culturales de Aragón. La tesis básica de la que se parte plantea que en territorios rurales sin gran tradición turística previa no es suficiente con disponer y valorizar los recursos culturalesambientales para promover un turismo rural capaz de revitalizar el territorio, en definitiva, que esos recursos son condición necesaria pero no asaz. Es preciso, pues, de una parte, que la oferta de recursos se complemente con otra de servicios y equipamientos para la atención y acogida de los turistas, lo que hará más probable asegurar su presencia en todo el territorio, no sólo en los elementos más relevantes, y hará del territorio un proyecto más vivo y sostenible. Y, por otro lado, que la acción pública inicial se oriente a cubrir las carencias y a realizar una labor de sensibilización para movilizar el interés de la iniciativa empresarial privada. Al final, deberá haber coordinación entre unas y otras acciones para hacer posible que el patrimonio sirva como yacimiento de nuevos empleos al servicio del desarrollo socioterritorial. Desde esas premisas, la hipótesis de trabajo es que la mera existencia del Parque Cultural de Albarracín no ha revertido sobre el territorio en forma de desarrollo socioeconómico; explicar y comprender las razones, pese a las potencialidades de esa figura, constituyen los objetivos más concretos de este artículo.

\section{Territorio y recursos patrimoniales}

El espacio geográfico nunca es fruto del azar; en su elaboración como realidad tangible, es decir, como hecho geográfico, intervienen múltiples elementos y factores 
que interactúan de forma dinámica en el plano espacio-temporal. Pero como los factores que confluyen en su construcción no son siempre los mismos, ni aunque lo sean intervienen con la misma intensidad, ni tan siquiera el mismo factor lo hace de manera sincrónica en todos los lugares, de ello deriva que la variedad (tanto con connotaciones de diversidad como de desequilibrio) y, consecuentemente, la singularidad regional sean dos ideas consustanciales al concepto de espacio geográfico. Añadido a lo precedente, señalar que el grupo humano es el principal artífice de esa construcción, eso sí, en función de sus patrones culturales, de sus capacidades científico-tecnológicas y teniendo en cuenta los recursos ofertados por el medio; pero puesto que esos patrones y capacidades se modifican con el tiempo, la dimensión evolutiva también va a estar presente en la variedad y singularidad regional y en el paisaje en el que se resuelve la percepción de cada hecho geográfico.

Cuando se delimita y localiza el área donde se produce, es decir, se concreta el escenario del hecho geográfico, pasa a recibir la denominación de territorio. Este es el nodo de arranque que nos interesa, porque se ha convertido en un elemento clave para el desarrollo, posiblemente porque el concepto empieza a utilizarse con propiedad (como hecho geográfico complejo producto de la acción de un grupo humano que modifica el medio) y no como sinónimo de espacio (soporte, oferente de recursos y receptor de impactos). Esto es importante, hasta el extremo de que dos espacios con elementos de características y valor parecidos pueden dar lugar a territorios distintos de cambiar los agentes presentes, públicos y privados, endógenos y exógenos y los procesos dominantes; es decir, pueden originar modelos territoriales diferentes, entendiendo por ello los modos de ocupar y aprovechar el espacio que progresivamente desarrollan los agentes en función de los recursos disponibles y de valorización más eficiente, de las redes sociales imperantes, de los conocimientos técnicos explícitos, de las necesidades sociales e individuales reales y percibidas y de las interacciones con otros territorios (relaciones comerciales, movilidad de las personas, etcétera).

Al territorio se le asigna un carácter de actor fundamental en las políticas de desarrollo (Moncayo, 2002 y Esparcia, 2007) y los objetivos y las acciones particulares que emanan de ellas, es decir, el impulso activo del desarrollo económico y social, descansan en las particularidades territoriales (el valor de lo local en el marco de lo global). Desde esta premisa se reivindica el valor de unas políticas que deben descansar en el aprovechamiento de recursos particulares (endógenos) con demanda suficiente y de ello puede emanar la reinvención de los territorios, si de su aplicación derivan modificaciones del modelo preexistente que den lugar a un funcionamiento más eficiente del territorio.

Con todo, el territorio no deja de ser también un oferente de recursos para el desarrollo socioeconómico, en unos casos ya valorizados y que por ello constituyen una fortaleza insuficientemente aprovechada si de su aprovechamiento no ha derivado el 
resultado esperado o deseable, en otros latente, aunque de ser susceptibles de atender a una oportunidad, desde su valorización, pueden pasar a la categoría de fortalezas territoriales. Tanto desde una hipótesis como desde la otra, la condición básica para que puedan ser calificados como recurso radica en que atiendan a una demanda real de aprovechamiento y satisfagan una necesidad insuficientemente atendida. Y como quiera que el combinado de recursos disponibles tiende a ser particular, de la misma manera que es difícil encontrar dos territorios iguales, la esencia del discurso del desarrollo territorial acaba descansando en la singularidad de cada territorio ligada al aprovechamiento de sus recursos endógenos. Dichos recursos no son sólo naturales-ambientales, o demográficos, o agrarios, o industriales, o patrimoniales, considerados de forma individual, antes bien, los recursos, identificados con los componentes del capital territorial, se evalúan concebidos como un todo (el capital disponible al servicio de la competitividad territorial -Observatorio Leader, 1999-), en asimilación al propio concepto de territorio, de carácter globalizador y sistémico. Incluso la denominación de los recursos cambia y en lugar de hablar de materias primas, o de fuentes de energía, o de agua, se habla de recursos ambientales (como percepción aglutinadora de las interacciones entre los componentes del medio natural), o en lugar de hacerlo de población se habla de recursos sociales (como dimensión que incluye no sólo al número de individuos y su estructura demográfica, sino que además tiene en cuenta sus valores, la cultura, la formación, su visión del territorio, sus instituciones, el modelo de gobernanza, etcétera).

También es importante el carácter de sostenibilidad que como objetivo anima a las políticas de desarrollo que se están implementando en la actualidad (y ello aun con toda la indefinición que caracteriza la aplicabilidad de un concepto tan flexible como es éste). Lo sostenible se concibe como territorial, por ser el resultado final de los objetivos de sostenibilidad ambiental, social y económica y porque sólo desde la acción sostenible sobre el capital territorial es posible disponer de territorios competitivos. Acciones tradicionales orientadas a maximizar la acumulación y/o generación de medios productivos se combinan con otras como las de adopción y/o génesis de innovaciones (es decir, la dimensión productiva en íntima conexión con el territorio -Esparcia, 2007-), las de conservación y/o aprovechamiento racional del capital ambiental y las de generación y/o disponibilidad de capital social. A la postre, en este nuevo paradigma del desarrollo el territorio ya no es sólo un elemento circunstancial en el crecimiento económico (es decir, que recibe los impactos del crecimiento, en positivo o en negativo, y evoluciona en función de ellos); ahora, más bien, se concibe como una estructura activa, un verdadero actor del desarrollo, aunque puede dar lugar a situaciones de crecimiento, estancamiento o regresión (Veltz, 1999). Lo cierto es que los territorios cambian, responden a los estímulos internos y externos, se adaptan y readaptan, porque en el fondo nunca dejan de ser sino sistemas abiertos, cuyo funcionamiento depende de su finalidad, y están determinados por el ambiente y el entorno. 
Aunque no existe ninguna política de desarrollo de carácter holístico puro, porque la realidad induce la imposibilidad práctica de intervenir desde y sobre todas las variables del capital territorial y tanto más cuando el tamaño del territorio adquiere una cierta dimensión, un ejemplo de acción territorial de desarrollo próximo a esa concepción son los Parques Culturales de Aragón.

Los parques culturales constituyen una propuesta de ordenación territorial-rural basada en el binomio cultura/naturaleza, precisamente el eje que a juicio de numerosos autores (Sabaté, 2004) va a ser dominante en estos inicios del siglo XXI, frente al acento puesto sobre la población y/o el desarrollo industrial más propios del XX y ello con énfasis máximo en territorios de escasa extensión, de ubicación no siempre adecuada para inducir oportunidades de desarrollo y cuya funcionalidad se ha visto alterada por los cambios ligados a la sucesión de dos modelos de aprovechamiento del espacio, productivista en primer término y con tendencia a postproductivista más tarde.

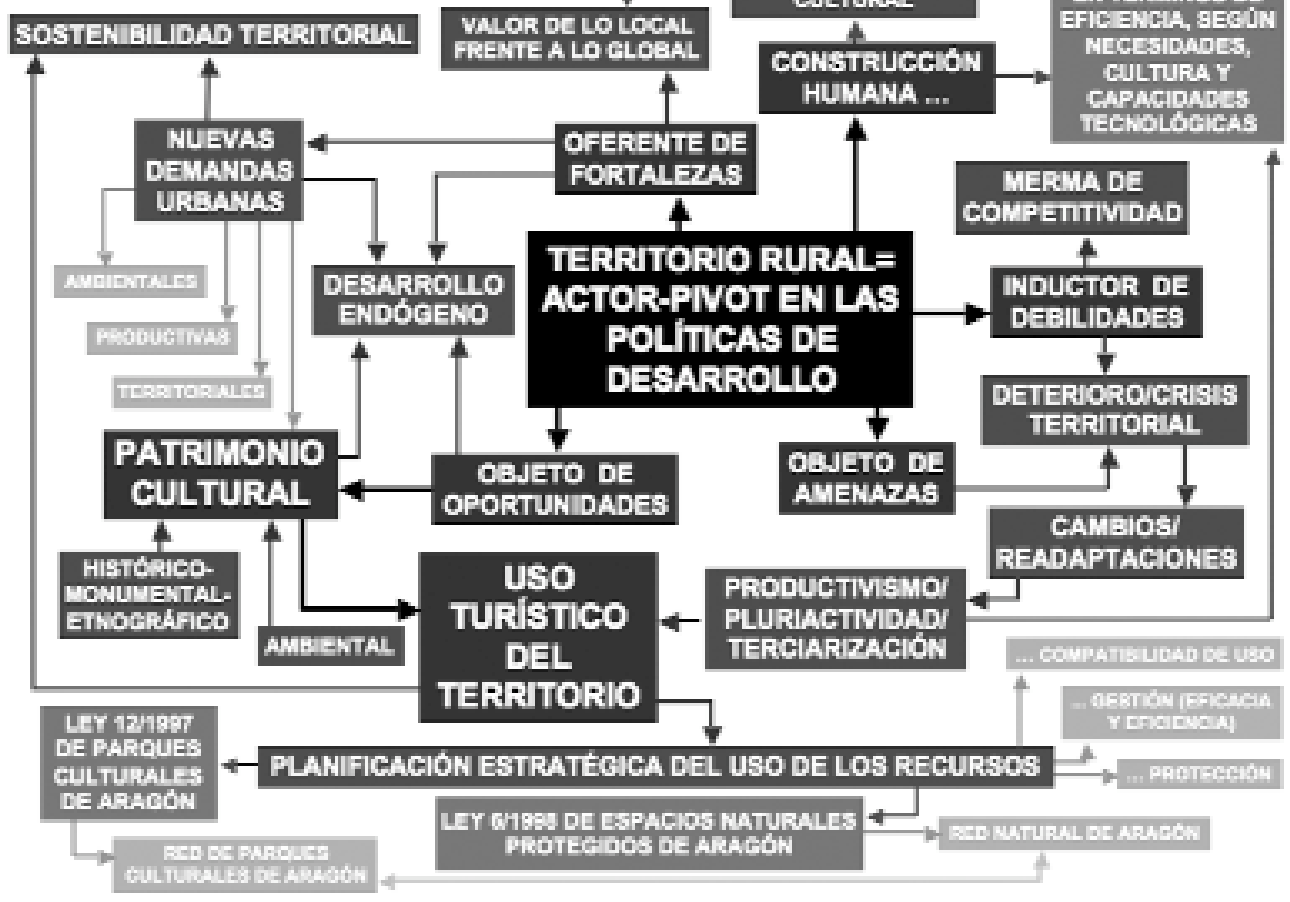

Figura 1: Marco conceptual: territorio, patrimonio y usos turísticos. Elaboración propia. 
La Ley de Parques Culturales plantea la delimitación de áreas rurales culturalmente individualizadas, en las que el territorio es el elemento y factor estructurante del desarrollo desde una finalidad genérica de cohesión económica y social, un territorio que se ha organizado durante un largo periodo histórico y originado un paisaje singular de alto valor patrimonial-ambiental. Ello induce fortalezas conectadas con algunas de las oportunidades derivadas de las nuevas demandas urbanas sobre la ruralidad (ambientales y productivas), concretadas en un uso-consumo del patrimonio cultural rural desde un aprovechamiento de tipo turístico que se combina con los tradicionales, entre los que la acción agro-ganadero-forestal deberá seguir siendo básica para el mantenimiento del paisaje cultural. Se asume que el aprovechamiento turístico facilita acciones de desarrollo con alta capacidad de arrastre socioeconómico en ámbitos rurales y que es capaz, a la vez, de garantizar la transición desde sociedades productivistas en crisis hacia sociedades terciarias, con una fase intermedia de orden pluriactivo, así como de evitar o sustituir "el barbecho espacial" (Bielza, 1999) derivado de la readaptación de los territorios rurales como resultado de la crisis de aquellas actividades productivas tradicionales que no se han adaptado progresivamente a esa etapa de pluriactividad; en último extremo, porque la desaparición de los aprovechamientos tradicionales tiene lugar en un contexto de crisis con génesis ex-novo de un nuevo modelo.

Cada parque acaba teniendo como fin la ordenación global del territorio articulada desde la perspectiva del patrimonio cultural, lo que implica la necesidad de coordinar los diferentes instrumentos de planificación urbana, ambiental, turística y territorial disponibles, con especial atención sobre los aprovechamientos tradicionales del suelo (Bernad, 2001).

\section{Los Parques Culturales}

\subsection{El patrimonio cultural}

La ley aragonesa 12/1997 señala que un parque cultural estará constituido por un territorio que contenga elementos relevantes del patrimonio cultural, integrados en un marco físico de valor paisajístico y/o ecológico singular, por lo que gozará de promoción y protección global en su conjunto y con especiales medidas de protección para los elementos más relevantes.

Patrimonio cultural y medio ambiente son la materia prima que hace posible la delimitación y puesta en marcha de un parque cultural. Pero no es fácil alcanzar una definición de consenso sobre qué es el patrimonio cultural. Las acepciones que ha 
recibido son variadas: desde su significado como colección histórica, o como sedimento de la parcela cultural, o como conformador de la identidad sociocultural, hasta su significación como modelo de referencia (LLull, 2005). La Conferencia Mundial sobre Políticas Culturales organizada por la UNESCO en 1982, determinó que "el Patrimonio Cultural de un pueblo comprende las obras de sus artistas, arquitectos, músicos, escritores y sabios, así como las creaciones anónimas surgidas del alma popular y el conjunto de valores que dan sentido a la vida, es decir, las obras materiales y no materiales que expresan la creatividad de ese pueblo; la lengua, los ritos, las creencias, los lugares y monumentos históricos, la literatura, las obras de arte y los archivos y bibliotecas".

El concepto de "patrimonio" también tiene que ver con los bienes y derechos que posee una persona o institución. Pero cuando incorpora la palabra "cultural" especifica un conjunto que incluye pautas de comportamiento, valores, símbolos e ideas y herencia, aspectos que pueden ser tangibles o intangibles, y la expresión "patrimonio cultural" pasa a expresar el conjunto de aspectos de una cultura que es necesario rescatar y cuidar y que en nuestra opinión incluyen al entorno ambiental de esas manifestaciones culturales, porque influye de forma determinante sobre ellas, a la vez que con ellas configura el paisaje cultural. Así pues, el patrimonio cultural acaba siendo visible mediante el paisaje resultante "de todas y cada una de las producciones de cualquiera de los ámbitos de la vida en sociedad y reflejo del mundo mental de quien las crea y utiliza, de donde proviene su valor inmaterial" (Fernández, 2006). Esas producciones son resultado de la actividad modificadora del hombre, también sobre los componentes del medio natural (paisaje natural), por lo que el valor del paisaje cultural, en cuanto que ámbito geográfico asociado a un evento, a una actividad o a un personaje, que contiene valores estéticos y culturales (Sabaté, 2004), deriva de la percepción que suscitan los elementos patrimoniales propiamente dichos (histórico-artístico-etnográficos) ubicados en un entorno natural del que no son independientes ni en su significación (por la imagen de comunidad que ofrece, por la identidad a la que da lugar, por la excepcionalidad que lo caracteriza, etcétera), ni en su aprovechamiento (como valor de consumo ligado a los valores estético y de ocio), ni en su competitividad (como suma de los de aprovechamiento y significación -Zouain, 2007-).

Ya se ha señalado que el patrimonio cultural subsume la idea de dinamismo, porque los elementos que lo configuran se construyen partiendo de la base de lo preexistente, que siempre se visualizaba mediante otro paisaje que es más o menos modificado; el patrimonio se ha elaborado de forma acumulativa a lo largo de la historia y sobre él son perceptibles las huellas de los diferentes grupos que han intervenido. Cuando el dinamismo es sostenible, de la construcción deriva un valor positivo en forma de escenario en equilibrio frágil e inestable y cualquier intervención ulterior sobre alguno o algunos de sus componentes dará lugar a un nuevo paisaje. Y tam- 
bién es inestable su valor de uso, porque depende de los parámetros culturales básicos del grupo social de cuya acción deriva la construcción, de una parte, y de los valores vigentes en el conjunto social externo que en un momento determinado accede a él y opta por consumirlo en términos de disfrute cultural y/o de ocio, de otra. Su valor como elemento de desarrollo tiende a derivar de ese uso, real o potencial.

La consideración del patrimonio cultural como recurso endógeno de desarrollo otorga plenitud al territorio, porque el patrimonio cultural-ambiental da lugar a un hecho geográfico individualizable mediante un límite que lo separa de otros hechos patrimoniales. En términos de desarrollo territorial, desde una aproximación utilitarista, el patrimonio es un agente y bien económico (que tiene, por ello, un valor de uso directo, en el sentido de ser susceptible de generar ingresos económicos) y también de identidad social que hay que proteger (Domínguez y Cuenca, 2005) para garantizar un uso equilibrado y sostenible del mismo.

El patrimonio cultural de los pueblos se ha revalorizado con el paso del tiempo, en Europa especialmente desde la década de los sesenta del siglo XX, en la misma medida en la que se ha consolidado la existencia de un turismo de masas consumidor de cultura también de masas (Manito, 2006). De una parte, ello ha dado lugar al desarrollo de un potente sector de gestión cultural, tanto público como privado, que ha convertido a los ciudadanos en espectadores y consumidores de patrimonio desde una orientación del mismo hacia el ocio y el turismo (hay quien habla de vulgarización de la cultura derivada de la masiva promoción de algunos de sus componentes -García, 2001-), como resultado de la consolidación de la cultura como una alternativa interesante para ocupar el tiempo libre de las personas. Por otra, la gestión cultural (en global) es un nicho laboral cada vez más importante ${ }^{2}$. Finalmente, la conjunción entre su carácter de yacimiento de empleo (Aragón, 2003), el movimiento de personas derivado de su aprovechamiento-consumo-disfrute (en definitiva, recurso económico) y su condición de recurso siempre existente, aunque con frecuencia insuficientemente valorizado, son las razones que conducen a que sea un elemento cada vez más presente en las políticas de desarrollo, en especial las rurales, aunque también en las de carácter urbano, utilizando en este segundo caso, casi siempre, el patrimonio monumental-histórico.

En algunos territorios, el patrimonio, convertido en producto turístico, acaba siendo objeto de un consumo masificado (Gotilla, 2001), lo que conduce a la necesi-

${ }^{2}$ Sobre este valor de nicho laboral son muy interesantes las reflexiones realizadas por J. Delors en el Libro Blanco sobre Competitividad, Crecimiento y Empleo, cuando habla de cuatro grupos y de 19 ámbitos de actividad; el tercer grupo se orienta hacia los servicios culturales y el ocio, y en él se integran todas las actividades del sector turístico, el audiovisual, la valorización del patrimonio cultural y el desarrollo cultural local. En esta misma dirección insisten distintos informes del INEM. 
dad de su protección y salvaguarda ${ }^{3}$. En el objetivo de propiciar un aprovechamiento sostenible del patrimonio (en otras palabras, hacer compatibles aprovechamiento -conducta humana- y conservación -derivada del interés social-, teniendo en cuenta el entorno en el que se ubican los bienes culturales, es decir, considerando los activos culturales y ambientales sobre los que se basa la acción de desarrollo turístico) y en su capacidad como recurso de desarrollo local, está el origen de los parques culturales, de un lado, y la gestión privada no lucrativa en los procesos culturales, por otro.

Su aprovechamiento no deja de ser, además, una acción de valorización de lo local frente a lo global, con una marcada componente social, identitaria y económica, por la cantidad de agentes que intervienen en el proceso y a los que sirve, lo que facilita la obtención de beneficios económicos, sociales y culturales, tales como formación, creación de empleo y génesis de nuevas fuentes de ingresos. Es por lo anterior que acaba siendo un instrumento de desarrollo local y regional (Toselli, 2006), sin duda favorecido por el carácter transversal de la cultura puesto de manifiesto en la Conferencia de Berlín sobre Política Cultural Europea (noviembre de 2004).

Si bien, creemos firmemente que tampoco es una panacea de desarrollo, en el sentido de estrategia de aplicabilidad indiscriminada para cualquier territorio, por cinco razones. Porque la competencia interterritorial como recurso endógeno de desarrollo a la que da lugar es muy alta (de nuevo, el principio de competitividad entre los lugares en la escala global). Porque el valor de los recursos disponibles es dispar y no siempre se adecua al gusto de los consumidores, lo que abre el camino potencial a intervenciones capaces de desvirtuar el valor original del paisaje cultural. Porque la capacidad de absorción de nuevos impactos sin que sus valores se modifiquen hasta el extremo de generar un nuevo patrimonio también difiere de unos casos a otros. Porque las oportunidades particulares de las regiones, con frecuencia derivadas de su localización teniendo en cuenta el contexto, no son coincidentes. Y porque no existe evidencia empírica suficiente para demostrar que la potenciación del binomio patrimonio cultural-turismo vaya a tener siempre un impacto claro en la evolución de la población y de la renta de algunos medios rurales, tal y como demuestran Precedo y Míguez (2007).

Con todo, también es cierto que el desarrollo de una industria turística ligada al patrimonio cultural puede llegar a adquirir en algunos casos el rol de "motor" en procesos de desarrollo socioeconómico, a nuestro juicio los menos, salvo en ámbitos prioritariamente urbanos que se benefician de la economía de escala propia de su

\footnotetext{
${ }^{3}$ La propia Ley General de Patrimonio Histórico de 1985 plantea que el uso más importante que debe otorgarse a los bienes culturales es el estudio y disfrute por parte de la mayor cantidad posible de población (Llull, 2005)
} 
condición urbana; en los más, tiende a corresponderle una participación complementaria, aunque extraordinariamente eficaz para los objetivos de diversificación y crecimiento económico, multifuncionalidad, complementariedad, equidad social en el proceso de redistribución de los beneficios de la actividad al conjunto de la sociedad y, en consecuencia, de sostenibilidad territorial. En los posibles casos de medio rural con acción económica polarizada sobre el aprovechamiento de su patrimonio, creemos que esa es una circunstancia que puede llegar a originar una nueva categoría de ruralidad.

\subsection{La Ley de Parques Culturales de Aragón}

Con la Ley de Parques Culturales de Aragón, esta Comunidad Autónoma dispone de una legislación única en el panorama de la conservación/gestión/ordenación/aprovechamiento del patrimonio cultural. Aunque ha sido la primera en tener esta figura, actualmente también existe en otras partes, con esa misma (Comunidad Valenciana) u otras denominaciones, como ecomuseo (de origen francés), museo integral (en el ámbito latinoamericano), museo al aire libre (en los países escandinavos, Alemania y Estados Unidos) o parque patrimonial (de raíz americana); la denominación parque cultural también figura como órgano específico de gestión de territorios con valores naturales-culturales específicos en el caso de la Ley de Patrimonio Histórico de Andalucía. Finalmente, apuntar que los parques culturales aragoneses incluyen objetivos similares a los de otras figuras asociadas al patrimonio natural, con especial referencia al modelo de parques naturales; la filosofía que los anima entronca con la idea de patrimonialización de los paisajes, teniendo en cuenta sus valores culturales y naturales, propugnada en el Convenio Europeo del Paisaje (Consejo de Europa, Florencia, 2000).

El parque cultural constituye una evolución del museo cerrado tradicional, o museo-institución (Ten, 2004), tanto de carácter histórico como antropológico, que se extiende a todo el territorio delimitado por el parque, asimilable a un ámbito con características comunes y singulares en la mayor cantidad posible de manifestaciones culturales y naturales. Así pues, la esencia del parque es su territorio, que figura como sustento de los hechos complejos de una cultura que se expresa y exhibe en una variada presencia de elementos y formas. Cada parque se conforma a partir de todas las manifestaciones culturales existentes en su territorio (esto es, in situ, en su ambiente natural), desde las materiales (yacimientos arqueológicos, monumentos, herramientas, paisajes, etcétera) a las inmateriales (creencias, costumbres, folclore, etcétera), todo ello teniendo en cuenta que la participación ciudadana en su valorización, protección y aprovechamiento es esencial para la consolidación del parque, lo que a juicio de Hernando (2001 y 2003) convierte al proyecto en un museo vivo. Y lo anterior sin olvidar que el término parque alude directamente al mundo del ocio 
y del entretenimiento, razón que explica su carácter de estímulo al desarrollo cultural y económico, pero además, dado que su delimitación se realiza a escala local, tiende a existir un alta correlación entre desarrollo sostenible y turismo (Sharpely, 2000 y 2003, citado por Cánoves, 2006).

La ley asume en su articulado los principios explicitados en las líneas precedentes, y entre sus objetivos (que señalan por dónde deberán orientarse las acciones posteriores) figuran el diseño de estrategias y medidas para el fomento de la protección del patrimonio cultural y natural, la conservación y mejora paisajística, el desarrollo de prácticas agrarias respetuosas con el medio ambiente, la proyección didáctica y formativa de los recursos patrimoniales, la animación sociocultural, la información al público en general, los programas de formación en pedagogía del patrimonio y su divulgación, principalmente entre escolares, la recuperación de actividades y manifestaciones culturales tradicionales y el fomento de la artesanía, el turismo rural cultural y ambiental, incluidos los alojamientos de turismo rural, la construcción y mantenimiento de senderos, recorridos naturales, culturales y paisajísticos, así como la recuperación y puesta en valor de la vías tradicionales de comunicación.

También combina la protección del patrimonio cultural con su gestión sostenible (Hernández y Giné, 2002). Es decir, por un lado, se explicita que hay que tener en cuenta todas las manifestaciones nacidas de la cultura humana (se incluyen los patrimonios histórico, artístico, arquitectónico, arqueológico, antropológico, paleontológico, etnológico, museístico, paisajístico, industrial, agrícola y artesanal), incluso aquellas que no siendo directamente producidas por la actividad cultural hayan podido afectar o influir en ella (patrimonios geológico, botánico, etcétera), con la idea de su conservación y difusión. Por otro, se da contenido a la gestión del patrimonio cultural, mediante tres estructuras: patronato, consejo rector y gerencia. En el trasfondo de la ley figura también la finalidad de la gestión estratégica del patrimonio mediante la elaboración del denominado Plan del Parque, al modo de plan director del mismo, en el que deben figurar los objetivos, las actuaciones a desarrollar para cumplirlos y los elementos patrimoniales sobre los que se va a actuar; en definitiva, es un documento único de planificación que, priorizando la protección del patrimonio cultural, debe procurar la coordinación de los instrumentos de la planificación urbanística, ambiental, turística y territorial disponibles. El plan debe garantizar la sostenibilidad de las acciones, tanto de las orientadas a valorizar recursos como en lo relativo a las destinadas a atender la demanda de consumo de esos recursos, en una doble dirección, por la población local, primera beneficiaria de cualquier acción de revalorización de los activos patrimoniales propios (porque forman parte de su bagaje cultural y de su identidad colectiva), y por los visitantes, que así pueden disfrutar de los recursos disponiendo, paralelamente, de servicios turísticos.

Pero la Ley de Parques Culturales no sólo es importante por la definición de contenidos y objetivos que presenta, también lo es por la consolidación de una línea de 
financiación a la que deben comprometerse los ayuntamientos afectados por la delimitación de cada parque y el propio Gobierno de Aragón, fomentando, además, la obtención de ingresos extraordinarios procedentes de otras administraciones locales, del Estado y de la U.E., así como de instituciones privadas y de donaciones de particulares al amparo de la normativa reguladora del mecenazgo. Desde este punto de vista, traza una senda de estabilidad y, sobre todo, de proyección estratégica del conjunto de intervenciones planificadas en el parque.

Su desarrollo mediante órdenes de incoación dio origen a cinco parques durante 1998, los de San Juan de la Peña y del Río Vero, ambos en Huesca, y los del Río Martín, del Maestrazgo y de Albarracín, en Teruel. Si bien, el proceso no está cerrado, porque hay nuevas demandas, como la del Parque Cultural de Sierra Menera (temáticamente centrado en torno al patrimonio industrial minero), o la del Parque Cultural de Monegros.

Una característica añadida y que pone el acento en el valor ambiental de cada parque se relaciona con la existencia combinada en el mismo espacio de la figura patrimonial que viene centrando nuestra atención, con otra u otras de protección natural de entre las incluidas en la Red Natural de Aragón (Parque Natural, Paisaje Protegido, Monumento Natural, ZEPA y LIC), eso sí no necesariamente coincidentes en sus límites con los de cada parque, o también con un espacio no perteneciente en su totalidad al ámbito de gestión de los parques culturales ${ }^{4}$.

Así pues, el combinado de recursos presentes en cada parque cultural es especialmente importante, lo que supone un valor añadido pensando en la eficacia potencial de su valorización como elementos de aprovechamiento turístico y para el ocio, teniendo en cuenta, además, que la existencia de todas estas figuras de protección permite garantizar con cierta seguridad la ausencia de impactos negativos, a la vez que facilita un aprovechamiento de los recursos ambientalmente sostenible.

\footnotetext{
${ }^{4}$ Tales como: el Parque Natural Sierra y Cañones de Guara; los Paisaje Protegidos de San Juan de la Peña y Monte Oroel, y de los Pinares de Rodeno; el Monumento Natural de las Grutas de Cristal de Molinos; las ZEPAs 01-ES0000015-Sierra y Cañones de Guara, 19-ES0000284-Sotos y carrizales del río Aragón, 20-ES0000285-San Juan de la Peña y Peña Oroel, 22-ES0000287-Sierras de Santo Domingo y Caballera y río Onsella, 37-ES0000303 Desfiladeros del río Martín, 40-ES0000306-Río GuadalopeMaestrazgo, 42-ES0000308-Parameras de Pozondón; y los LICs: 48-ES2410074-Yesos de Barbastro, 50ES2410025-Sierra y Cañones de Guara, 52-ES2410067-La Guarguera, 53-ES2410062-Río Gas, 54-ES2410061San Juan de la Peña y Oroel, 55-ES2410017-Río Aragón (Jaca), 56-ES2410060-Río Aragón-Canal de Berdún, 58-ES2410004-San Juan de la Peña, 62-ES2410064-Sierras de Santo Domingo y Caballera, 112-ES2420113Parque Cultural del Río Martín, 113-ES2420112-Las Planetas-Claverías, 117-ES2430095-Bajo Martín, 130ES2420145-Cueva de Baticambras, 131-ES2420149-Sima del Polo, 132-ES2420146-Cueva de la Solana, 133ES2420148-Cueva del Recuenco, 134-ES2420124-Muelas y Estrechos del río Guadalope, 136-ES2420126-Maestrazgo y Sierra de Gúdar, 146-ES2420134-Sabinar de San Blas, 147-ES2420135-Cuenca del Ebrón, 150-ES2420039-Rodeno de Albarracín y 151-ES2420142-Sabinar de Monterde de Albarracín.
} 


\section{El Parque Cultural de Albarracín}

El Parque Cultural de Albarracín (en adelante PCA) comprende los términos municipales de Rodenas, Pozondón, Albarracín, Bezas y Tormón, en total 45.250 Has (el "término municipal" de Albarracín no se incluye en su totalidad). Está ubicado, en la rama castellana del Sistema Ibérico, en el tercio oriental de la Comunidad Histórica de Albarracín, entre los paisajes de rodeno (arenisca de color rojo de la facies Buntsandstein) y de pinares de los Montes Universales y el paisaje de caliza con modelado kárstico (campos de dolinas) y cubrimiento por carrascales y sabinares de los llanos de Pozondón, en un ámbito de montaña media mediterránea.

Como nexo común al territorio-parque figura la existencia de manifestaciones de arte rupestre pictórico y grabado en una treintena de abrigos, de ellos veintiséis accesibles al público. Además, otros valores culturales destacables son: el conjunto histórico, murallas y acueducto de la ciudad de Albarracín, la zona arqueológica de Piazo de la Virgen en Albarracín, la iglesia de Santa Catalina en Rodenas y el Paisaje Protegido de los Pinares de Rodeno (Pinus pinaster).

\subsection{Contexto socio-espacial}

El adjetivo "rural" es el que mejor sintetiza las características territoriales del PCA (y en general de la comarca de Albarracín); en concreto un rural profundo, marcado por un aislamiento territorial derivado de la difícil accesibilidad y la falta de armadura urbana (sólo Albarracín, que es la capital comarcal, supera ligeramente los 1.000 habitantes). Añadido a lo anterior, la debilidad del tejido productivo, la extremadamente baja densidad de población, el alto grado de envejecimiento y el déficit de jóvenes están acelerando su desertización económica y funcional y la merma progresiva de su competitividad territorial.

Según el Padrón Municipal de Habitantes de 2007, en los municipios del PCA viven 1.113 habitantes (densidad media de 7,8 habitantes $/ \mathrm{km}^{2}$ ), de los que el $34,3 \%$ tienen 65 o más años y sólo un 14,6 menos de 15 (Censo de Población de 2001). La evolución demográfica ha sido de signo estructuralmente negativo (desde 1900 se han perdido un $63 \%$ de los efectivos censados aquel año), y sigue siéndolo en la actualidad; así, el saldo demográfico anual medio para el periodo comprendido entre 1991 y 2004 es del $-3,81 \%$ y ello pese a que en este mismo periodo el migratorio viene siendo del 5,64\%. La tendencia demográfica hace prever que en municipios como Tormón su futuro en cuanto que lugares de poblamiento permanente sea problemático. Atendiendo a la estructura de la población activa, la debilidad de la actividad primaria es significativa (11,0\% de los activos), la secundaria es relativamente impor- 


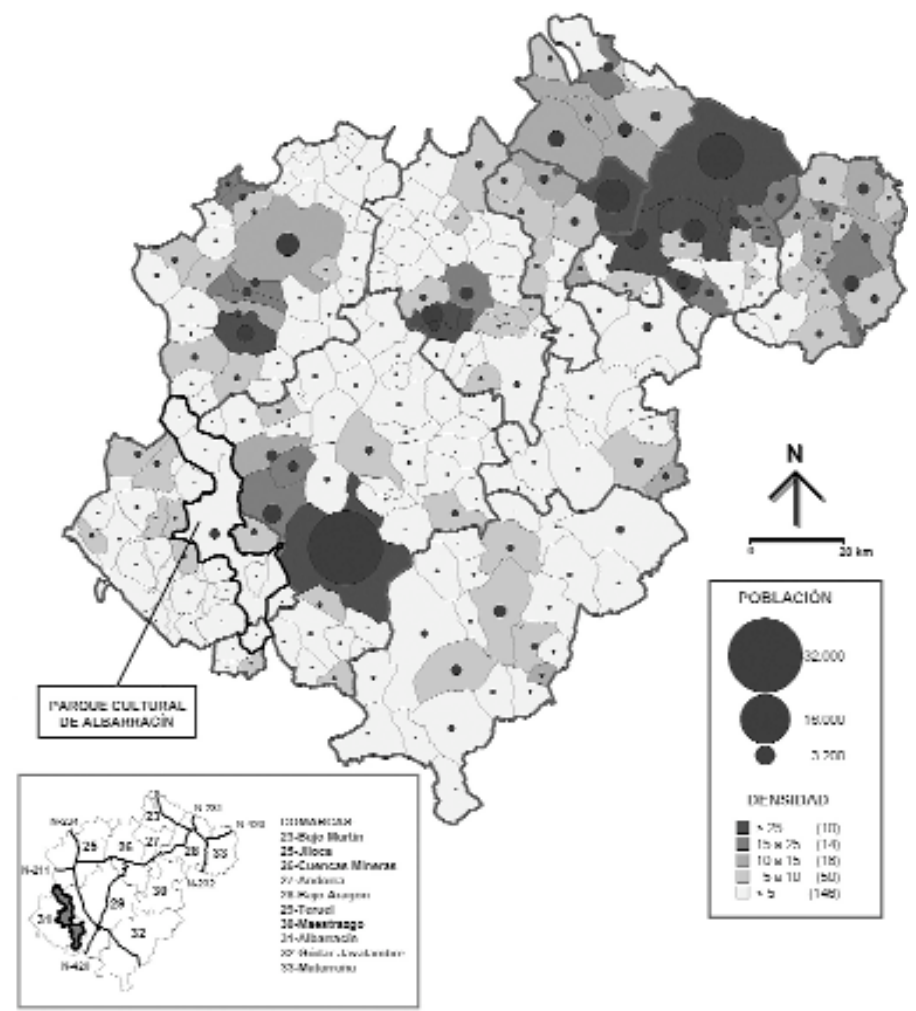

Figura 2. Distribución de la población y densidad (en habitantes/km²). Provincia de Teruel, año 2005.

tante $(24,7 \%)$ y existe una polarización clara hacia el terciario $(64,3 \%)$, lo que viene a indicar la existencia de una transición desde una economía tradicional (agraria) hacia otra moderna, transición con desagrarización inicial y presencia creciente de empresas terciarias, hasta el extremo de que los ratios de licencias terciarias/1.000 habitantes son sensiblemente superiores a los valores medios de la provincia y de la mayor parte de las comarcas turolenses. El terciario (es decir, servicios competitivos) está orientado hacia la restauración y hostelería (que son las actividades que más crecen desde el punto de vista de los establecimientos) y espacialmente aparece concentrado en el municipio de Albarracín; el resto de las actividades son escasas (con la excepción del comercio minorista). La estructura demográfica tiene un fuerte impacto sobre la localización de los servicios públicos (no competitivos), que por razones de capitalidad administrativa, mayor envergadura demográfica y de dinamismo económico relativo, también se concentran en Albarracín. 


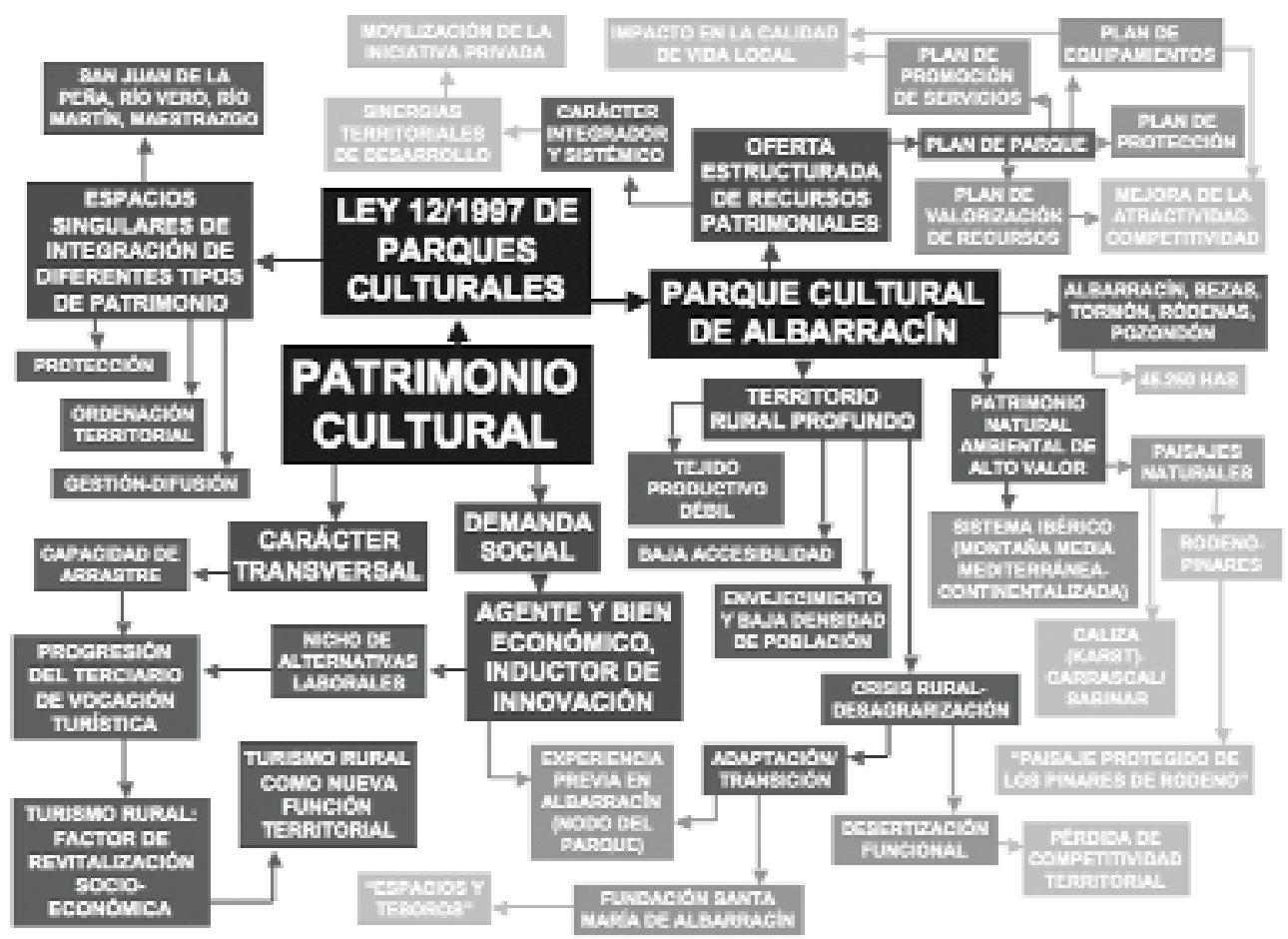

Figura 3. Patrimonio y Parque Cultural de Albarracín. Elaboración propia.

Con todo, la estructura productiva de la comarca de Albarracín adolece de una cierta especialización relativa en agricultura (la aportación del sector al VAB comarcal es 2,6 veces superior a la media regional y 1,3 a la provincial), construcción y servicios; mientras, la debilidad industrial es manifiesta. En el caso de los municipios del parque, la especialización terciaria supera a la comarcal y disminuye el de la primaria, hasta el extremo de desaparecer como tal característica; mientras, el valor de la construcción se mantiene en términos similares. Así pues, a partir del valor añadido que generan las actividades más importantes, podemos valorar la transición aludida de muy primitiva y que no ha redundado, por ahora, en un incremento significativo de los niveles de renta "per capita", lo que merma competitividad interna a este territorio para hacer frente a la despoblación. La comarca de Albarracín presenta uno de los valores de renta disponible más reducidos de entre las comarcas aragonesas, 9.427 euros/per capita en 2002, frente a una media provincial y regional de 12.909 y 13.731 euros, respectivamente; a ello colabora también la existencia de una alta tasa de población dependiente y jubilada, mayoritariamente del régimen especial agrario, por lo que la transferencia pública por esta vía tampoco mejora las cifras. 


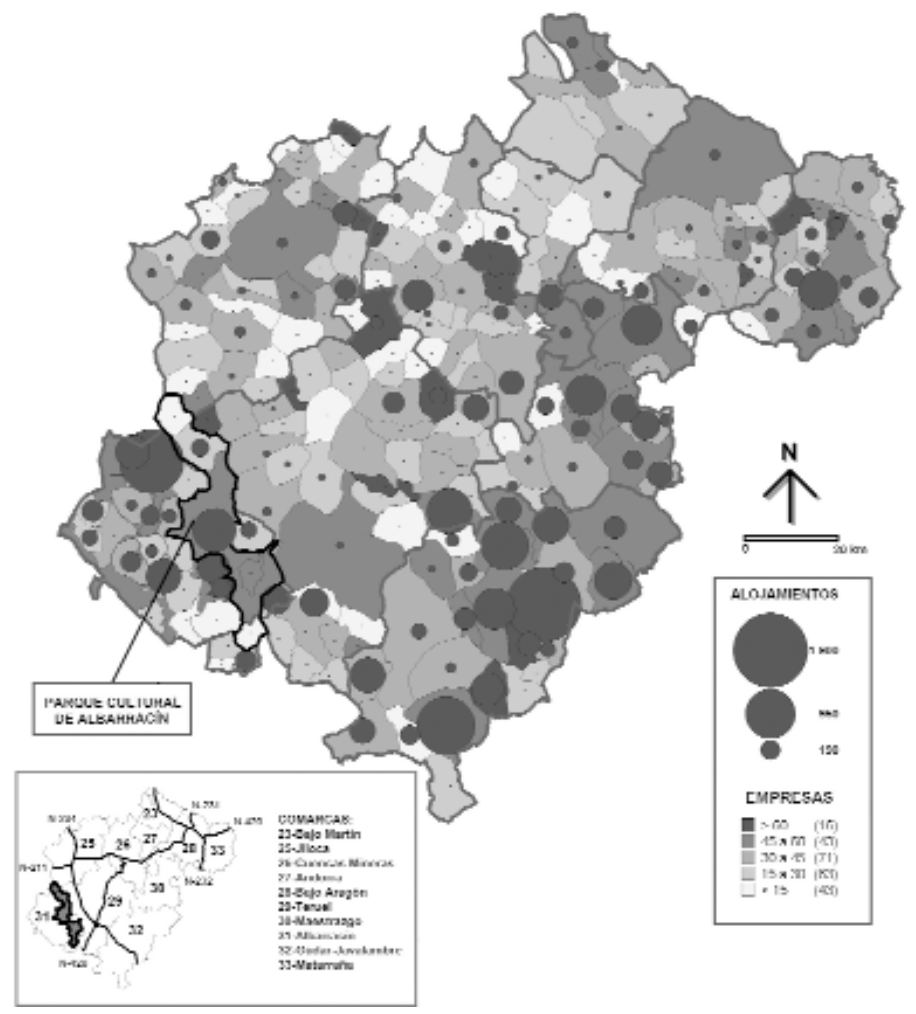

Figura 4. Distribución de alojamientos hoteleros y de empresas, por mil habitantes. Provincia de Teruel, año 2004.

Desde principios de la década de los 90 del siglo XX se vienen desarrollando en esta comarca diferentes programas de desarrollo rural (Leader I, Leader II y Leader +) que ayudan a explicar esa terciarización de la actividad económica. Sin embargo, pese a la importancia de las acciones desarrolladas, la recesión demográfica ha continuado, lo que es síntoma del deterioro funcional de este territorio, en el que no es fácil inducir una dinámica de desarrollo endógeno y sostenible que de lugar al crecimiento demo-económico. Con todo, a su recurso más preciado, el patrimonio natural-cultural, sí que corresponde un alto potencial de dinamismo económico en el marco del turismo cultural y de ocio, lo que está siendo especialmente perceptible en Albarracín, que individualmente se beneficia, además, de una dilatada trayectoria como destino turístico de interior; la oferta de servicios turísticos es insuficiente y no se ha desarrollado pese a la existencia del PCA. 
Albarracín es un caso aparte en las escalas comarcal y del PCA, por su carácter de motor demográfico, económico y cultural en ambas. Además, en este municipio existe otra estructura muy interesante y que participa activamente en su desarrollo y consolidación como centro cultural de interior, nos referimos a la Fundación Santa María de Albarracín, entidad sin ánimo de lucro que viene ejecutando desde hace muchos años una acción orientada a la valorización de los recursos patrimoniales de la ciudad, con intervenciones en la recuperación y gestión del patrimonio histórico y en el desarrollo y promoción cultural de la misma.

\begin{tabular}{|c|c|c|c|c|}
\hline Comarca & $\begin{array}{l}N . \underline{a} \\
\text { mun. }\end{array}$ & $\begin{array}{c}\text { Valor } \\
\text { patrimonial } \\
\text { de las } \\
\text { comarcas }\end{array}$ & $\begin{array}{c}\text { Municipio con mayor } \\
\text { valor patrimonial }\end{array}$ & $\begin{array}{c}\text { Media } \\
\text { valor } \\
\text { patrim./ } \\
\text { mun. }\end{array}$ \\
\hline ALBARRACÍN & 25 & 726 & ALBARRACÍN, 229 & $29 ’ 0$ \\
\hline ANDORRA & 9 & 239 & OLIETE, 46 & $26 \cdot 5$ \\
\hline BAJO ARAGÓN & 20 & 613 & ALCAÑIZ, 118 & $30 \prime 6$ \\
\hline BAJO MARTÍN & 9 & 201 & HIJAR, 51 & $22 ' 3$ \\
\hline CUENCAS MINERAS & 30 & 546 & MONTALBÁN, 57 & $18 ' 2$ \\
\hline GÚDAR-JAVALAMBRE & 24 & 987 & RUBIELOS DE MORA, 124 & $41 ’ 1$ \\
\hline JILOCA & 40 & 983 & CALAMOCHA, 162 & $24 ’ 6$ \\
\hline MAESTRAZGO & 15 & 755 & MIRAMBEL, 116 & $50 ’ 3$ \\
\hline MATARRAÑA & 18 & 771 & CALACEITE, 93 & $42 ' 8$ \\
\hline COMUNIDAD DE TERUEL & 46 & 1.441 & TERUEL, 319 & 31 '3 \\
\hline
\end{tabular}

FUENTE: Hernándo (2007).

En un trabajo recientemente publicado sobre los resultados del programa INTERREG SUDOE III-B denominado REVITAL (Hernándo, 2007), se ha valorado la relación existente entre el patrimonio cultural, en cuanto que oferente de "capital" para la revitalización socioeconómica de áreas rurales deprimidas, y la dotación de servicios turísticos para la atención de los visitantes y con capacidad añadida para generar un impacto positivo sobre la calidad de vida local en la provincia de Teruel. Se identifican disfunciones muy interesantes en la relación patrimonio-servicios, lo que lleva a la conclusión de que el potencial patrimonial, independientemente de su interés y del impacto que pueda tener para generar nuevo tejido socioeconómico, difícilmente inducirá impactos positivos si no existe infraestructura turística paralela. Los resultados indican que Albarracín destaca en el marco provincial; en conjunto, su patrimonio representa un 3,0 \% del provincial (concentra sólo un 0,8 \% de la población) y por servicios y equipamientos turísticos ocupa, junto a Alcañiz, la primera posición en el ranking turolense (con índice de valor 13). De considerar el conjunto de los municipios del PCA (Tormón 14, Ródenas 21, Pozondón 24, Bezas 5 y Albarracín 219), el valor patrimonial asciende hasta el 3,9\%, si bien, el índice de dotaciones terciarias pierde valor relativo por la heterogeneidad implícita a las bajas aportaciones de Tormón (1) y Rodenas (2). 


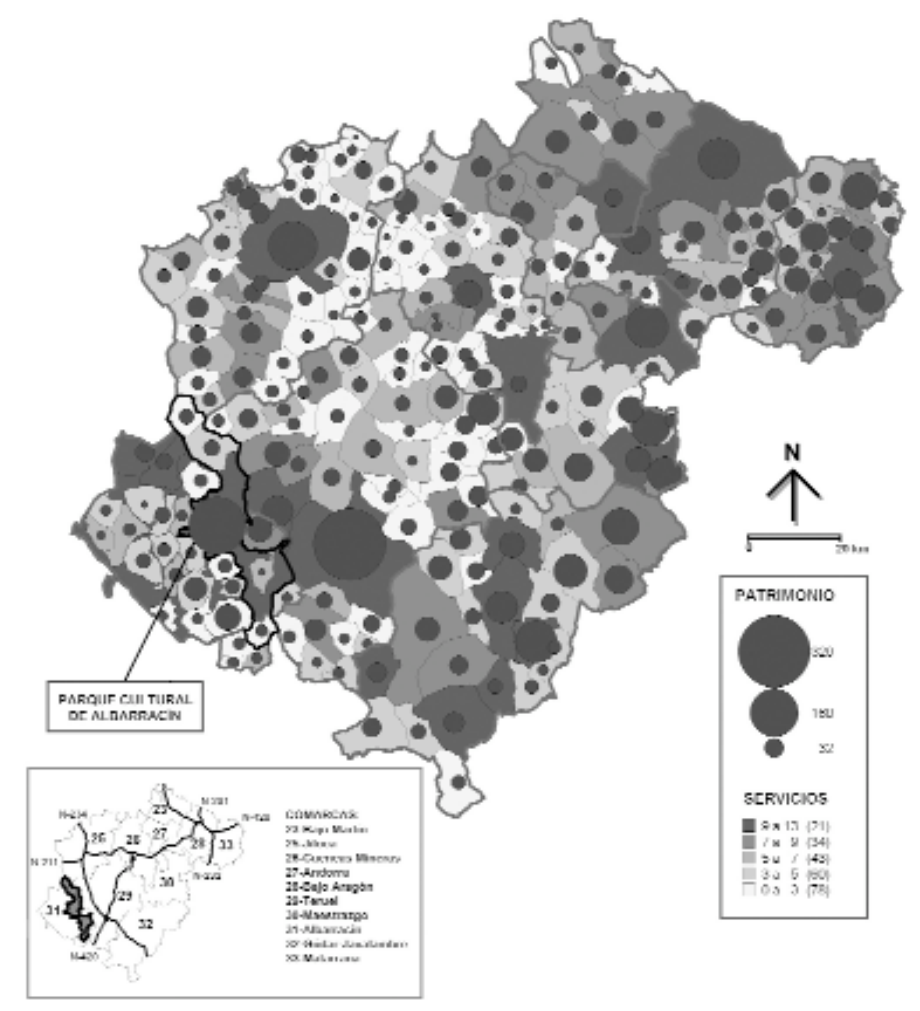

Figura 5. Valor patrimonial e índice de servicios turísticos disponibles. Provincia de Teruel, año 2005.

El alto valor patrimonial del territorio del parque, unido a la amplia difusión y conocimiento externo de la "marca Albarracín", explican el importante número de visitas/año que acoge. Según información de la Oficina de Turismo de Albarracín, la ciudad ha recibido en el periodo 2003-2006 una media de 136.000 turistas/año, con máximos mensuales de unos 20.000 en abril y agosto; de ellos, como mínimo 35.000 han practicado auténtico turismo cultural, son los visitantes de la oferta "Albarracín, espacios y tesoros", gestionada por la Fundación Santa María, y 50.000 han visitado los abrigos con pinturas rupestres del Parque Cultural, una masa de "clientes", pues, muy importante, aunque excesivamente concentrada en los recursos de la ciudad y en las pinturas próximas a ella y que en potencia se podría redirigir hacia los ofertados por el resto del PCA y la comarca; lo que no quiere decir que no los visiten, pues un mínimo de entre 50.000 y 80.000 visitantes no se sabe a ciencia cierta que otros recursos patrimoniales al margen de los citados utilizan durante su estancia. 


\subsection{Los elementos del PCA}

Desde la publicación de la orden de incoación del PCA, se han desarrollado una serie de actuaciones que lo están configurando como una estructura organizada, tanto desde el punto de vista de los elementos culturales, en cuanto que recursos para el desarrollo, como desde la perspectiva de la oferta para la atención de los visitantes, nos referimos a la disponibilidad de servicios y equipamientos tan básicos como restauración, alojamientos, espacios expositivos, etcétera, que no existen en casi ningún municipio, con la excepción ya conocida de la ciudad de Albarracín, cuya dinámica es distinta y la gestión de sus recursos turísticos ajena a la del resto del parque.

El parque se está "construyendo" en la actualidad, tanto desde el punto de vista de las actuaciones de adecuación, mantenimiento y protección de los recursos culturales, como desde la elaboración de su Plan de Gestión, pendiente todavía de redacción definitiva, lo que supone una debilidad que lastra negativamente su consolidación como territorio con vocación de aprovechamiento turístico-cultural. Otra se relaciona con el proceso de delimitación del parque, del que han quedado fuera algunas áreas con características similares, como los municipios de Almohaja y Peracense, lo que hubiera contribuido a optimizar la masa crítica de recursos ambientales-patrimoniales disponibles. También existe un déficit en el plano de la labor de sensibilización sobre la existencia e importancia de esta estructura en cuanto que elemento de dinamización socioeconómica, ambiental y cultural, en definitiva territorial, que no se ha desarrollado suficientemente, ni hacia los habitantes ni hacia las instituciones locales.

Otras debilidades añadidas afectan a capítulos tales como la gestión del parque, con una carencia casi absoluta de personal técnico. A la promoción-difusión interna y externa de esta estructura y de los recursos que oferta, realmente escasa. También es importante la desconexión entre el Parque, la Fundación Santa María de Albarracín, el programa Leader +, las comarcas con competencias administrativas en este territorio y la Diputación Provincial de Teruel; aunque todas ejecutan planes de valorización y protección del patrimonio al servicio de un desarrollo sostenible, lo hacen como compartimentos estancos, sin lugar a la génesis de sinergias por aumento de la masa crítica que supondría el sumatorio de acciones organizadas en un plan coordinado. Tampoco se detecta una implicación real de las autoridades municipales con el proyecto, en el caso de Albarracín la acción es individualizada, en el de los otros municipios la situación es más de compás de espera de acontecimientos que de acción orientada a dinamizar esta estructura, que en el fondo lo es de innovación; posiblemente, el grado de desvitalización humana alcanzado sea parcialmente causa, aunque a ello no es ajeno la falta de liderazgo social e institucional durante el proceso de génesis de la declaración de parque, de arriba-abajo y sin contar ni con la implicación activa de los actores locales públicos, ni con el interés de la población 
local. Finalmente, esa ausencia de implicación de los actores locales también es extrapolable a la acción privada, que por ahora mantiene una cuota de participación mínima, con la excepción de la gestión de algunas instalaciones financiadas por el PCA.

Las distintas actuaciones, aunque derivan de objetivos precisos, no cuentan con la perspectiva planificadora que a medio plazo otorgaría disponer del referido Plan de Parque, a la vez que en su financiación sólo ha intervenido el Gobierno de Aragón, que ha destinado unos 700.000 euros en cinco anualidades, no así los ayuntamientos $\mathrm{u}$ otras instituciones locales como las comarcas (Sierra de Albarracín y Comunidad de Teruel $)^{5}$; en consecuencia, han sido menos numerosas de lo deseable, de menor impacto territorial y están dilatando excesivamente la disponibilidad del parque entendido como una oferta consolidada.

En el proceso es posible identificar tres etapas. La primera se desarrolló entre 2000 y 2001, con acciones orientadas a proteger y potenciar aquellos activos culturales que dan sentido al PCA y que constituyen la base para el desarrollo posterior de otras actividades: limpiar senderos y caminos y sustituir elementos de señalización (ruta de senderismo del río Ebrón y ruta entre Tormón y Bezas), inventariar y delimitar los entornos de protección de los enclaves con arte rupestre, proteger mediante cerramientos algunos abrigos que estaban al aire libre y recuperar la música tradicional de la Sierra. Durante la segunda se ha actuado en la construcción de un albergue en Tormón, además de ofertar servicios de cafetería y bar que no existían previamente; en la reforma de una casa rural en Rodenas; en la rehabilitación del antiguo horno municipal en Pozondón, inicialmente con la idea de ubicar en él un restaurante; en la reparación del antiguo cine de Bezas, para destinarlo a Centro de Interpretación del PCA y en la construcción de una hospedería; con esas actuaciones se ha favorecido la disponibilidad de equipamientos con los que atender a los visitantes y colaborar en la mejoría de la calidad de vida local; en realidad, salvo Albarracín, el resto de los municipios presentan una de sus principales debilidades en la oferta de servicios hoteleros y de restauración. En la tercera, iniciada en 2004 y todavía inconclusa, se está progresando en la dirección trazada en la anterior, es decir, la oferta de equipamientos para mejorar la capacidad de atracción turística, dotando a cada localidad de infraestructuras de exposición y didáctica de su patrimonio cultural; las actuaciones se han centrado en la construcción de un Centro de Interpretación de la Piedra de Rodeno en Rodenas, la utilización de un antiguo horno como Centro de Interpretación de la Arquitectura Tradicional en Pozondón, el diseño del Centro de Actividades de la Naturaleza en una antigua casa de forestal en Tormón, y se ha progresado en la construcción del Centro de Acogida de Visitantes del Parque Cultural en Bezas.

${ }^{5}$ El municipio de Bezas pertenece a esta comarca. 


\section{Reflexiones finales}

Territorio y recursos de desarrollo son variables indisociables cuya interacción origina que los segundos modelen el valor del primero, lo que avala la conveniencia del desarrollo desde la valorización de elementos endógenos con demanda real y desde un aprovechamiento sostenible. En caso contrario, el valor del territorio cambiará y/o se acabará modificando la oferta de recursos, en definitiva, el valor del capital territorial será distinto. Entre los recursos potencialmente valorizables para el desarrollo de medios rurales deprimidos figuran el denominado patrimonio cultural, entendido como un combinado formado por el patrimonio histórico y el patrimonio ambiental. Su conjunción da lugar a un paisaje de carácter, pues, humanizado. Mediante su valorización, al carácter tradicional del patrimonio como bien de identidad se añade el de agente y bien económico derivado de un uso de carácter turístico (los ciudadanos como espectadores y consumidores de patrimonio durante su tiempo de ocio). El aprovechamiento turístico se está revelando como un interesante yacimiento de empleo allí donde la transición desde el modelo productivista, esencialmente agrosilvo-ganadero, hacia otro postproductivista está afectada por dificultades para generar fuentes de empleo alternativas a la acción primaria, de una parte, y/o complementarias a ella, de otra.

Lo antedicho explica que el patrimonio, como recurso, esté cada vez más presente en las políticas públicas de desarrollo; una opción con cierta capacidad de arrastre sobre otros activos del capital territorial e inductora de la cultura de la innovación, pero que, paralelamente, exige una acción de protección y salvaguarda en orden a evitar un eventual "consumo" que deteriore el recurso; es decir, sostenibilidad de su explotación como interfase de conexión entre el aprovechamiento económico de los recursos, su capacidad para reportar beneficios al conjunto del cuerpo social y el mantenimiento de las condiciones ambientales-socioculturales. Obviamente, el problema básico reside en determinar el punto de equilibrio óptimo, que no es el mismo en todos los territorios; de no alcanzarlo, su deterioro puede acabar siendo causa de otros de tipo ambiental, funcional y humano, en definitiva territorial.

La Ley 12/1997 de Parques Culturales de Aragón es una acción pública con potencialidad para la dinamización socioeconómica local-rural, mediante la génesis de una oferta estructurada de recursos patrimoniales. En el marco de esa ley se encuadra el PCA, en el que se está interviniendo con la valorización de recursos turístico-patrimoniales en los municipios de su delimitación y la creación de una infraestructura de equipamientos de tipo expositivo y terciario, desde objetivos que tienen en cuenta la necesidad de ofertar alternativas laborales a la agricultura para frenar la despoblación, de garantizar el mantenimiento de los aprovechamientos del espacio y las costumbres tradicionales, de incrementar la disponibilidad de servicios básicos para la población local y de generar una oferta cultural capaz de sensibilizar a la población sobre el valor de su patrimonio en cuanto que activo de futuro. 


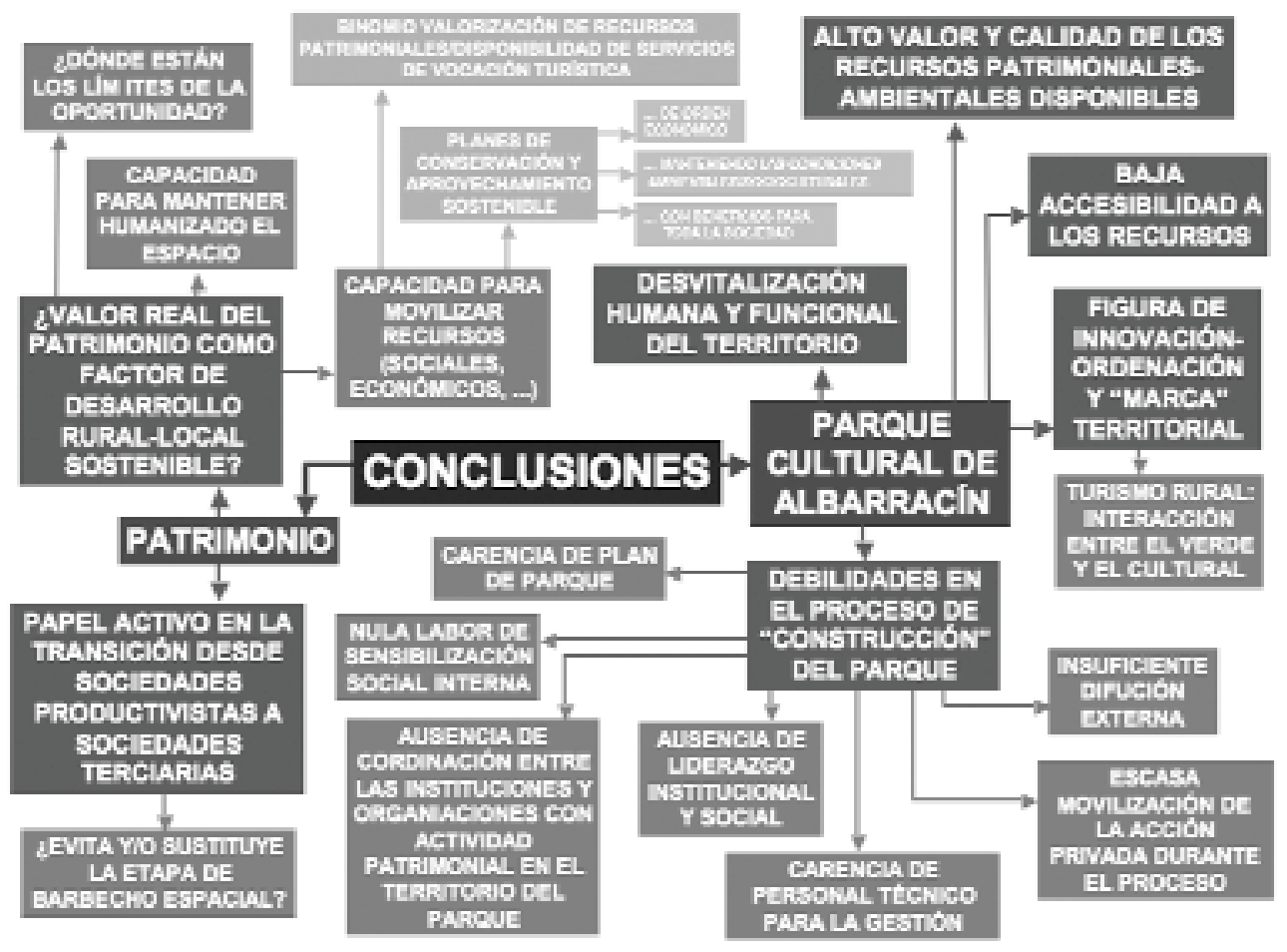

Figura 6. Conclusiones. Elaboración propia.

La elaboración de esta trabajo nos confirma la hipótesis acerca de la necesaria coordinación que debe presidir el binomio patrimonio cultural-infraestructura y servicios de vocación turística, ello desde la planificación de la gestión estratégica de la cultura y el medio ambiente en cuanto que factores de desarrollo en territorios rurales sometidos a una reestructuración productiva ligada a la "crisis-modificación" del sector agrario y la necesidad de potenciar actividades no agrarias para garantizar el mantenimiento del sistema tradicional de asentamientos y, por lo tanto, mantener vivo el proceso de humanización del espacio.

La senda trazada con las acciones ejecutadas parece adecuada al objetivo de generar una oferta patrimonial-ambiental y de ruralidad asimilada a tranquilidad, ocio y cultura. Creemos que incluyen un alto potencial de desarrollo socioeconómico local que, sin embargo, a fecha de hoy no se ha materializado en realidad incontestable (en definitiva, la inversión de la dinámica de deterioro humano y funcional), seguramente como consecuencia de la debilidad demográfica de los municipios más rurales del PCA, lo que sirve para explicar el déficit de iniciativas empresariales que los 
caracteriza y enfatiza la importancia del factor humano para el éxito de las políticas. Su capacidad para movilizar el interés de la población es manifiesta, pero se enfrenta a la ausencia de un liderazgo local, tanto por el lado de las instituciones como por el de los agentes sociales y económicos, posiblemente por la falta de sensibilización interna inicial; en esta tesitura, es difícil alcanzar el objetivo de romper el círculo vicioso existente entre las carencias de servicios y equipamientos locales, los déficits en la calidad de vida de la población y las dificultades para consolidar un flujo de turismo cultural, verde y/o de ocio generador de actividad económica. Tampoco deja de ser reseñable la carencia del Plan de Parque, que le conferiría auténtico valor como instrumento de ordenación territorial.

También el déficit en la accesibilidad al PCA es importante, aunque perderá impacto con la conclusión definitiva de la A-23, que discurre próxima, a lo que añadir la transformación de la línea ferroviaria convencional Cantábrico-Levante en línea de velocidad alta y el hipotético uso del aeródromo de Caudé (situado en las inmediaciones de Teruel) para el transporte de viajeros en conexión con la actividad de reciclado de aviones prevista en sus inmediaciones. Todo ello se combina con la proximidad a la ciudad de Teruel; es una circunstancia que deben aprovechar tanto Teruel como el PCA. También la existencia y actividad de la Fundación Santa María de Albarracín es importante, con la que, no lo olvidemos, comparte muchos objetivos generales y territorio de acción, lo que implica que la colaboración entre ambas estructuras es necesaria para obtener réditos de sinergia mutua.

El PCA, de una parte, no deja de ser una figura de innovación y de génesis de una marca territorial, capaz de aunar la valorización de los recursos patrimoniales como bien económico, con su protección y salvaguarda ante un eventual deterioro, en definitiva, de desarrollo sostenible. De otra, es una figura legislativa que proporciona un "balón de oxígeno" a la oportunidad que para lo local supone el aprovechamiento turístico-cultural de recursos endógenos de demanda global. Lo anterior, sin presuponer que este aprovechamiento sea panacea para invertir la tendencia de deterioro humano y funcional existente, aunque es cierto que puede colaborar para superar la "etapa de barbecho" que ha seguido a la crisis de la agricultura productivista, a la que en el caso de Albarracín se suman las de la extracción forestal y primera transformación de la madera.

Las dudas sobre esta dinámica sobrevienen cuando se reflexiona sobre sus límites, por varias razones. Porque llevada al extremo pudiera conducir a un nuevo productivismo en términos de "monocultivo poco sostenible". Porque no se ha evaluado el techo al que da lugar la oportunidad. Porque se desconoce el límite de la capacidad del PCA para mantener en progresión la necesidad de seguir mejorando la competitividad con respecto a otros territorios de vocación similar. Porque la eficacia de esta estructura disminuirá si la desvitalización humana del territorio supera ciertos 
límites. Y añadido a lo anterior, porque no se debe olvidar que la intervención con recursos públicos sólo será eficaz cuando logre movilizar a la iniciativa empresarial privada (el PCA es un ejemplo de manifiesta debilidad en este sentido) y cuando esa intervención sea fruto del consenso entre las administraciones con competencias en el territorio y los agentes sociales más dinámicos. Coincidimos con Cánoves y otros (2006) sobre los claroscuros que potencia el turismo rural en cualquiera de los tres ejes de la actividad: socieconómico, cultural y ambiental. Por el lado de lo socioeconómico destaca que aunque es cierto que colabora en la diversificación de las economías rurales, en la génesis de nuevos puestos de trabajo, en la reducción de las emigraciones y en contribuir al desarrollo endógeno, lo anterior ocurre en un contexto tal que los puestos de trabajo creados están afectados por un alto grado de precariedad, es una actividad que generalmente precisa del complemento de otras rentas y los beneficios generados pueden no llegar a repartirse de forma equilibrada en la comunidad. Mientras, por el lado de lo cultural, aunque ayuda a la recuperación y revitalización de la cultura local y proporciona oportunidades de intercambio cultural entre los residentes locales y los visitantes, por contra, puede artificializar la cultura local (convirtiéndola en poco más que una manufactura), alterar el equilibrio social en la comunidad y ser causa de ruptura en el dinamismo creativo cultural. Finalmente, en el eje medioambiental, aunque puede contribuir a la concienciación y sensibilización medioambiental de la población y a asegurar el mantenimiento de la actividad agrícola y del mosaico de paisajes, paralelamente puede ser causa de impactos ambientales como polución, residuos, contaminación acústica y/o luminosa y alteración del hábitat local de la flora y la fauna.

Es por todo ello que anteriormente se ha apuntado que el turismo no es una panacea, más bien es una opción y una oportunidad que puede ayudar a mantener vivos los territorios, a condición de que sea capaz de conciliar los objetivos de crecimiento económico, sostenibilidad ambiental-social y dinamismo creativo cultural.

Por último, esa idea de dinamismo creativo nos sugiere otras reflexiones añadidas, que también son parcialmente dudas con cierta dosis de perversidad al respecto de algunas de las finalidades de las políticas patrimoniales y el uso de estos recursos para el desarrollo territorial. Con frecuencia se olvida que la creatividad es una dimensión inherente a la cultura y, en consecuencia, al patrimonio corresponde un carácter dinámico y cambiante; normalmente aparece considerado como un dato relativamente estático (Berdoulay, 2002) y material en las políticas patrimoniales de conservación, cortando de esta forma la creatividad cultural y paisajística. No ponemos en tela de juicio la necesidad de proteger el patrimonio, sobre todo cuando su aprovechamiento sea insostenible, o cuando por carecer de uso se esté deteriorando irremisiblemente, o cuando otros aprovechamientos en el entorno generen residuos que lo destruyen; tan sólo especulamos preguntándonos hasta dónde se debe proteger a ultranza y porqué se debe admitir sin contestación la ruptura de la creatividad. Defendemos la pro- 
tección-conservación en el caso de elementos singulares, que por ello lo son de toda la sociedad (de la que lo ha generado y de la que puede disfrutarlo), e irreemplazables, pero no tanto cuando se reduce su singularidad o si se considera el paisaje cultural como una totalidad formada por elementos interrelacionados. Incluso, tenemos dudas sobre cómo se evalúa actualmente la singularidad; creemos que deriva más de planteamientos de orden estructuralista que funcionales y sistémicos y se hace en clave de cultura urbana y no de cultura propiamente territorial-local. Una sociedad como la actual, en la que "la cultura se ha convertido en un concepto en boga" (Leimgruber, 2002: 92), no admite fácilmente que el dinamismo del paisaje cultural implica evolución, cambios de uso y de valor, elaboración progresiva de formas nuevas, reelaboración de las antiguas, en definitiva, que el patrimonio del futuro se debe seguir construyendo y que la sociedad y los seres individuales que habitan el territorio deben seguir siendo los agentes básicos de esa construcción dinámica en la escala local, que también lo es de su identidad. Protección, aprovechamiento y dinamismo son los extremos de una realidad cultural no siempre fáciles de conciliar.

\section{Bibliografía}

Albertos, J. M. (2002) Cultura, innovación y desarrollo local. Boletín de la AGE, 34 , 229-244

Aragón, S (2003) Yacimientos de empleo, horizonte 2006. Círculo de Progreso. Consulta en línea: http://profesores.ie.edu/salvador_aragon/Documentacion/2003Yacimientos.pdf

Berdoulay, V. (2002) Sujeto y acción en la geografía cultural: el cambio sin concluir. Boletín de la AGE, 34, 51-61.

Bernad, P. (2001) Parques Culturales de Aragón: el Río Martín. Museo de Zaragoza, Boletín, 15, 205-218.

Bielza, V. (1999): Desarrollo sostenible, turismo rural y parques culturales. Cuadernos de Investigación Geográfica, 25, 125-137

Boletín Oficial de Aragón, Ley 12/1997 de 3 de diciembre, de Parques Culturales de Aragón. Consulta en línea: http://noti-
cias.juridicas.com/base_datos/CCAA/ar112-1997.html

Boletín Oficial de Aragón, Ley 6/1998 de 19 de mayo, de Espacios Naturales Protegidos de Aragón. Consulta en línea: http://noticias.juridicas.com/base_datos/C CAA/ar-16-1998.html

Boletín Oficial de Aragón, Ley 3/1999 de 10 de marzo, de Patrimonio Cultural Aragonés. Consulta en línea: http://noticias.juridicas.com/base_datos/CCAA/ar-131999.html

Cánoves, G., Villarino, M. y Herrera, L. (2006) Políticas públicas, turismo rural y sostenibilidad: difícil equilibrio. Boletín de la AGE, 41, 199-217.

Carvalho, P. (2004): Património e (re)descoberta dos territorios rurais. En NOGUÉS, S. (ed): El futuro de los espacios rurales, Santander, Servicio de Publicaciones de la Universidad de Cantabria. 
Claval, P. (2002) El enfoque cultural y las concepciones geográficas del espacio. Boletín de la AGE, 34, 21-39.

Comisión de las Comunidades Europeas (1993) Crecimiento, competitividad y empleo. Retos y pistas para entrar en el siglo XXI. Bruselas-Luxemburgo, Libro Blanco, COM (93) 700.

Council of Europe (2000). European Landscape Convention. Congress of Local and Regional Authorities of Europe.

Domínguez, C. y Cuenca, J. M. (2005) Patrimonio e identidad para un espacio educativo multicultural. Análisis de concepciones y propuesta didáctica. Investigación en la Escuela, 56, 27-42.

Esparcia, J. (2007) Políticas e instrumentos de desarrollo territorial. En RUBIO, P. y SANZ, A. (coord): Investigación aplicada al desarrollo de territorios rurales frágiles, Zaragoza, Prensas UniversitariasUniversidad de Zaragoza.

Fernández, E. (2006) De tesoro ilustrado a recurso turístico: el cambiante significado del patrimonio cultural. PASOS, Revista de Turismo y Patrimonio Cultural, 1, 1-12.

García, J. C. (2001) Qué son y de dónde vienen los Portales de Internet: comparativa de algunos portales de ocio. Educación y Biblioteca: 123, 73-79.

Goytia, A. (2001) El fenómeno del ocio ¿Amenaza para el patrimonio y el turismo cultural?. $A D O Z, 21,28-38$.

Hernández, M. L. y Giné, H. (2002) Los parques culturales de Aragón: un ejemplo pionero en la protección y gestión turística de espacios culturales y naturales. En FERNÁNDEZ, F. y otros (eds): Turismo y transformaciones urbanas en el siglo XXI, Almería, Universidad de Almería, p. 199207.

Hernando, P. L. (2001) El Parque Cultural de Albarracín. I Jornadas de Gestión del
Patrimonio Cultural Aragonés, Uncastillo (Zaragoza), Asociación Española de Gestores del Patrimonio Cultural.

Hernando, P. L. (2003) Usos del patrimonio cultural y natural, el ejemplo del Parque Cultural de Albarracín, Teruel. Jornadas de Urdaibai sobre desarrollo sostenible, Bermeo (Bilbao), Centro de la UNESCO en el País Vasc, Unesco-Etxea.

Hernando, P. L., Simón, P. y Pascual, M. C. (2007) Valorización del patrimonio. En RUBIO, P. y SANZ, A. (coord): Investigación aplicada al desarrollo de territorios rurales frágiles, Zaragoza, Prensas Universitarias-Universidad de Zaragoza.

Instituto Nacional de Empleo (2000): El desarrollo del ámbito rural y su incidencia en la generación de empleo.

Leimgruber, W. (2002) Actores, valores y cultura. Reflexiones acerca del papel de la cultura en geografía. Boletín de la $A G E$, 34, 91-103.

Llull, J. (2005) Evolución del concepto y de la significación social del patrimonio cultural. Arte, Individuo y Sociedad, 17, 175204.

Manito, F. (2006) Cultura y estrategia de ciudad. La centralidad del sector cultural en la agenda local. CIDEU. Consulta en línea: www.cideu.org

Moncayo, E., (2002) Nuevos enfoques teóricos, evolución de las políticas regionales e impacto territorial de la globalización, Santiago de Chile, Instituto Latinoamericano y del Caribe de Planificación Económica y Social (ILPES), CEPAL, Naciones Unidas.

Observatorio LEADER (1999) Innovación el medio rural: la competitividad territorial. Cuaderno no 6, Fascículo 1.

Precedo, A. y Míguez, A. (2007) La actividad turística como factor de desarrollo en el 
sistema español de asentamientos (19752002). Boletín de la AGE, 45, 191-211.

Rubio, P. y Hernando P. L. (2007) Desarrollo local y patrimonio cultural. Los parques culturales. En III Coloquio HispanoFrancés de Geografía Rural, Los espacios naturales protegidos, Baeza, Universidad Internacional de Andalucía, Sede Antonio Machado

Ruiz, J. L. (2004) Patrimonio y desarrollo local en Andalucía. Boletín de la AGE, 38, 101114.

Sabate, J. (2004) Paisajes culturales.El patrimonio como recurso básico para un nuevo modelo de desarrollo. URBAN, 9: 829.

Ten, A. (2004) ¿Qué es un museo? Hacia una definición general de los museos de nuestro tiempo Consulta en línea: http://www.uv.es/ten/p61.html
Toselli, C. (2006) Algunas reflexiones sobre el turismo cultural. PASOS, Revista de Turismo y Patrimonio Cultural, 2, 175182.

UNESCO (1982) Declaración de México sobre politicas culturales. Conferencia mundial sobre las políticas culturales, México D.F. Consulta en línea: http://portal.unesco.org/culture/es/files/1 2762/11295424031mexico_sp.pdf/mexico_ sp.pdf

Veltz, P., (1999) Mundialización, Ciudades y Territorios, Barcelona, Ariel Geografía.

Wagner, P. L. (2002) Cultura y geografía: un ensayo reflexivo. Boletín de la AGE, 34, $41-50$.

Zouain, G. (2007) El patrimonio cultural en la construcción de indicadores de desarrollo. Consulta en línea: http://www.fundacioabertis.org/rcs_jor/zouain.pdf 